\title{
A Collaborative Capstone Industry Project for Community College Students
}

\section{Dr. Ibrahim F. Zeid, Northeastern University}

Ibrahim Zaid is a professor of mechanical, industrial, and manufacturing engineering at Northeastern University. He received his Ph.D. degree from the University of Akron. Zeid has an international background. He received his B.S. (with highest honor) and M.S. from Cairo University in Egypt. He has received various honors and awards both in Egypt and the United States. He is the recipient of both the Northeastern Excellence in Teaching Award and the SAE Ralph R. Teetor National Educational Award.

\section{Marina Bograd, MassBay Community College \\ Dr. Chitra Javdekar, Mass Bay Community College}

Dean, Division of Science, Technology, Engineering, and Mathematics 


\title{
A Collaborative Capstone Industry Project for Community College Students
}

\author{
Abstract \\ The Community College, located in Wellesley, MA offers two certificates in Advanced Manufacturing: \\ Manufacturing Technology and Manufacturing Innovation. Each certificate can be completed within a \\ year. The final semester is dedicated to a paid industry internship where students are supervised by \\ both company and faculty advisors while learning on the job skills at a partnering company. The \\ internship is mandatory for the students to graduate. Students may work up to 40 hours a week and are \\ paid up to $\$ 15 /$ hour. These internships can often lead to full-time employment.
}

Sometimes it is difficult for students to secure paid internships. This paper describes an innovative model where a partnering company can provide a project for the students to work on in-house at the college campus. In turn, the Community College compensates the students for 80 hours @ $\$ 15 /$ hour, the minimum number of hours to fulfill the internship requirement for the certificate. The Community College faculty advisor of the project, acts as a liaison between the company and the students. Moreover, as part of the NSF funded project, the Community College works collaboratively with a local major University. Thus, the Community College faculty advisor is aided by a Ph.D. graduate student from the University. As a result of these collaborations, the team consists of three or four Community College students, a Community College faculty advisor, an industry advisor from the sponsoring company that provides the project, and a Ph.D. graduate student. All stakeholders work together during the semester to complete an industry project.

The partnering company initially provided multiple projects and after careful consideration, the students ultimately selected one of them. The project goal was to design robot safety cages around some manufacturing equipment to safeguard the machine operator from moving robotic equipment traveling at above-head level. The company provided the project specs. The students set to design and simulate cages design using SolidWorks CAD/CAM software. Students, the faculty advisor, and the graduate student visited the company during the project execution and had regular contact with the company advisor, during the semester, to seek feedback and test their designs. By the end of the project, the students were able to successfully design new cages to meet the company requirements.

This paper describes the project in more detail, how team members worked together, the company's feedback, guidance to students, and the company's plans to implement the final design and build the cages. The paper also describes the lessons learned and the benefits to students, Community College faculty, and the company. Finally, the paper discusses future collaboration with the company and broader impact on programs at the college.

\section{Introduction}

Numerous studies have been done on the benefits of experiential education and student participation in relevant internships. Community College students, however, often face several challenges in finding and being able to participate in typical experiential learning opportunities, such as internships and co-op experiences. Internships in a technical field, such as manufacturing and engineering are often only available to upperclassmen moving to their third year of college and require students to work a 9-5 schedule for a designated period of time. The Community College student population is often nontraditional; many have full time jobs and family obligations that prevent them from participating in a traditional 9-5 temporary internship. 
Experiential learning is important at all levels including the exposure it provides for graduate students who aspire to teach, with an opportunity to work with non-traditional Community College students. Mentoring non-traditional Community College students, while working with Community College faculty, better prepares them for a future teaching career and increases opportunities for those who may aspire to teach in a Community College setting in the future.

This paper describes an off-site internship model, lessons learned, and stakeholder benefits for Community College manufacturing certificate students. In this project, a team of three Community College students was led by a graduate student from a major University to design a safety guarding solution for ejection molding machines in a manufacturing company. The group was advised by the company employee and a Community College faculty member.

\section{Benefits of Experiential Learning}

Experiential Learning as described by David Kolb, one of the founders of this theory, is "the process whereby knowledge is created through the transformation of experience. Knowledge results from the combination of grasping and transforming experience" (Kolb 1984, p. 41). Kolb's experiential learning theory describes how students absorb and use information and is commonly shown in a four stage cycle - concrete experience, observation of and reflection on that experience, formation of abstract concepts based upon the reflection, and testing the new concepts. ${ }^{1}$

A number of studies have shown the benefits of experiential learning and various models of integrating the concepts in the college curriculum. ${ }^{2}$ A common way of providing experiential learning to college students are internship and co-op experiences. In Liberal Education and America's Promise [LEAP] report, developed by the American Association of Colleges and Universities (AACU), internships were on the list of the top ten target categories for High-Impact Educational Practices. ${ }^{3}$ Kuh (2008) states that these "practices have been widely tested and have been shown to be beneficial for college students from many backgrounds. These practices take many different forms, depending on learner's characteristics and on institutional priorities and contexts." (p.1). ${ }^{4}$

Several organizations, including the Council for the Advancement of Standards in Higher Education (CAS), The National Society for Experiential Education (NSEE) and National Association of Colleges and Employers (NACE), provide a definition and the importance of incorporating internships into the curriculum:

- NACE defines internships as "a form of experiential learning that integrates knowledge and theory learned in the classroom with practical application and skills development in a professional setting. Internships give students the opportunity to gain valuable applied experience and make connections in professional fields they are considering for career paths; and give employers the opportunity to guide and evaluate talent" (NACE, 2011). ${ }^{5}$

- CAS developed a mission statement for the internship experience that states "The mission of Internship Programs (IP) is to engage students in planned, practical, educationally purposeful experiences in professional, work-related settings that relate to or complement students' academic and career goals." (Council for the Advancement of Standards in Higher Education [CAS], 2015, p.6). ${ }^{6}$

Various models of experiential learning and methods of incorporating it in the curriculum have emerged. Models include classroom projects, apprenticeship programs where students study and work part-time, internships where students work for a period of several months for an organization, or co-op programs 
where students work for longer periods in a relevant industry. These models may work for the traditional college student population, but are more challenging for a non-traditional college student.

Two challenges that the students often face are time and level of education. A career changer faces some challenges in being able to participate in a traditional internship experience. He/she may have job and family obligations as well as a lack of experience in his/her field of study. Traditional internships are typically short-term (around 3 months), often full-time 9-5 positions. An adult holding a full-time job to support a family would not be able to participate in this type of program, preventing him/her from gaining a valuable experience. The second challenge facing Community College students is their level of education when applying for internship positions. Often companies offer internship positions to those further along in their educational program. Some companies are reluctant to hire students with only two semesters of coursework. To ensure that all interested students are able to participate in an internship, a flexible internship model is necessary.

Much like undergraduate students, aspiring faculty also require varied experience. Traditionally doctoral students seek teaching positions but their primary teaching experience is limited to teaching assistant positions in a traditional undergraduate setting. They rarely get a chance to work with a diverse community college student population. Lack of this experience may limit their teaching opportunities.

\section{Manufacturing Certificate Program Overview}

An NSF funded project allowed for a team of faculty and staff from a Community College in Wellesley, MA and a University in Boston, MA to collaboratively develop two manufacturing certificate programs. One program was developed in Manufacturing Technology and the other in Manufacturing Innovation. The goal of the project was to help retrain liberal arts graduates to enter the advanced manufacturing sector, a technical area lacking qualified employees ${ }^{7}$.

The manufacturing sector in Massachusetts is very diverse and spans a number of industries ranging from medical device manufacturing to food and electronics. The tools used in each sector are just as diverse; including computer aided design, ejection molding, machining, laser cutting, and robotics. The goal of the two certificate programs was to provide a broad introduction to the manufacturing sector. To ensure that students are prepared to enter the workforce after two semesters of coursework, experiential learning has been infused across the program's curriculum.

Each of the two twenty five- credit certificate programs can be completed in three semesters. The program was designed with flexibility in mind to ensure that it could be completed by career changers with jobs, and family obligations. The curriculum includes required introductory industry relevant coursework, a selection of program elective courses, an internship preparation course, and an internship.

Many courses in the program are project based, modular, and are offered in a hybrid format with limited seat time on campus, and primarily offered in the evenings. Project and team based coursework further prepares students for the workforce. Hybrid and evening course format is conducive for those with other commitments such as employment and family obligations. Modular course structure allows additional flexibility where students with prior knowledge of a specific subject or special interest can be advised to substitute a different module, more suited to their needs. Modular structure can also attract those who might not need to participate in the entire program, but need a few additional skills for professional development. 
The Manufacturing Technology program focuses on more technical skills and includes courses such as basic Numerical Control Programming, Reverse Engineering, and Supply Chain Management. The Manufacturing Innovation program provides an introduction to manufacturing and is more business focused with courses such as new product development and entrepreneurship. Both certificate programs were designed to provide technical and business skill sets in addition to the liberal arts education and previous experiences that the students already possess.

To ensure that students are prepared to seek a job or an internship, they are required to take a onecredit Career Readiness and e-Portfolio course in the first semester of the program. In this course, students develop a resume, a professional on-line presence including a Linkedln profile and an online project portfolio which they continue to update throughout the program. They also learn about job search strategies and have opportunities to practice interview skills.

In the third semester of the program, students participate in an internship relevant to their area of study. Each student is required to complete a minimum of eighty hours in their internship. Along with the internship, students are enrolled in a one-credit Co-op Dialogue course where they can share and reflect on the experience. At the start of the internship students, their faculty advisor, and company supervisor complete a formal contract that includes intern's learning goals and objectives. Throughout the internship students keep an online internship experience journals sharing them with other internship participants and the faculty advisor. At the end of the internship interns and company supervisor participate in an anonymous survey. Intern evaluation is also completed by the company supervisor. The experiential internship component is an important part of the curriculum where students are able to apply the skills they have learned in the classroom.

Both programs are offered at the Community College making them more affordable. Community Colleges are open access institutions and much like other programs offered at a Community College, the two certificates are open to all and have enrolled students with different educational levels, previous employment backgrounds, and ages.

\section{The Off-Site Internship Experience}

Students enrolled in the Manufacturing Certificate programs are required to complete a minimum of eighty hours of work in a relevant industry internship as well as participate in the Co-op Dialogue course where they can reflect on the experience and share it with other students who are working at different sites. Not all students are able to participate in a traditional on-site internship due to employment and family obligations. The off-site internship model with flexible hours allows students to work on an industry relevant project while being remotely mentored by company and faculty advisors. This model is also conducive to involving a graduate student as an additional advisor, thus exposing the graduate student to a community college population.

In the summer of 2016, three graduating Manufacturing Technology students participated in the off-site internship designing safety cages for injection molding equipment used in a partnering manufacturing company. The company was in the process of moving to a new location and reconfiguring the new space. Students had to redesign the existing cage structure to fit the needs of the new space.

The off-site team consisted of the three interns, a faculty advisor, and the university graduate student. A company advisor worked with the off-site team to advise interns on the project and ensure that the company requirements were met. Grant funding was used to compensate students working on the 
project at the rate of $\$ 15 / \mathrm{hr}$. Although, in this project interns were paid through a grant, this experience would work similarly in an unpaid Internship with a course credit or can potentially be incorporated in a course as a project based experience.

Initially the company advisor provided a list of projects that could be completed remotely. Each project included a brief description, requirements, and constraints. The off-site team met to discuss the projects and selected one project that was of most interest - safety cage design.

Studies show that providing students a choice to work on projects that are of interest, empowers them making them intrinsically motivated to work on the project above and beyond the minimum requirement. In this case, the project selection was primarily made by the students and was based on their general interests, personal experiences, and background. All three students were interested in workplace safety and had relevant experiences in various settings including a restaurant and a semiconductor manufacturer.

Once the project was selected, the team came-up with a work plan and scheduled the following:

1. A time to visit the company

2. Weekly in-person meetings that worked with everyone's schedules

3. A check-in schedule with the company advisor

The off-site team decided that each student intern would work independently to create their own design solution. The team held regular weekly meetings to discuss progress and work through questions and concerns. Each solution was then presented to the company advisor for comments. Based on those comments, the interns combined their individual designs into one final design that the company plans to implement once fully moved in to their new space. Figure 1 below shows the final safety cage design that was developed by the group.

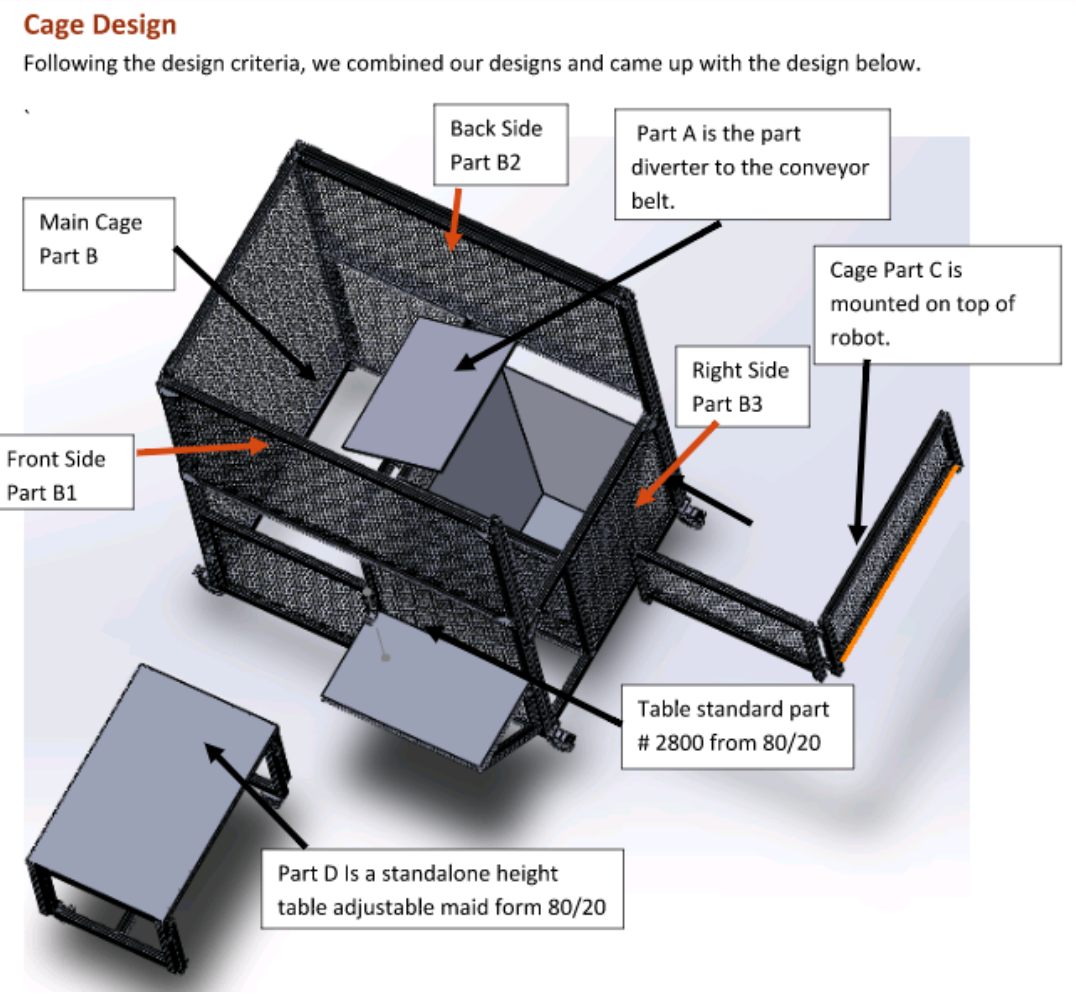

Figure 1 Final Cage Design 
In the first week of the internship, the team selected the project and did the initial research to learn more about the materials and environment around which they needed to design the cages. Then, led by the graduate student and faculty advisor, the team developed a list of questions for the company advisor as well as a list of things to investigate during the company visit. In the second week, the team visited the company, prepared questions for the company advisor, and took notes and dimensions of the materials needed to move forward with the project.

Throughout the eight weeks of the internship, interns worked independently on weekly tasks. On average, each intern spent eight to nine hours per week working on the project. Similarly to an online course, interns were able to set a schedule that worked with their other commitments and completed this project work at a time that was convenient to them. The off-site team met each week for one to two hours to recap the week and to create a plan for the following week. Throughout the week, the team communicated remotely via e-mail, and shared information electronically using a shared Google Drive. The company advisor joined the off-site team meetings on a biweekly basis by phone and attended the individual and team intern's presentations in-person.

Each student on the team brought with them a unique background, experiences, and work habits. Therefore each student approached the design and team collaboration very differently, offering unique solutions and focusing on a different aspect of the project. As one of the students described this process in his journal: "We have a design and there are parameters / constrictions placed on that design. It was up to us to figure out what design best fits the criteria given to us."

In week five, interns presented individual solutions to the company advisor. Each design satisfied given project requirements but each design had unique features. In his feedback to the interns, the company advisor selected features from each individual project that were most optimal. Based on the feedback, interns then worked together to combine their designs into one cohesive project. As one of the interns stated in his journal: "I guess you could say that we started as individual workers and showed the employer what we are capable of working alone. Then it turned into a group project and we are showing what we can do working as a team."

The graduate student from the University served as the project advisor and manager. She reviewed the intern's work and ensured that all necessary information was available to all project stakeholders. She provided periodic updates and questions to the team and worked closely with the students and faculty advisor, thus gaining experience working with the Community College population.

The faculty advisor served as the content expert on the project. She periodically reviewed student designs, advised the graduate student, and assisted with communication between the company and the team. She met with the team weekly. Having the graduate student lead the project and communicate with the interns was a benefit to the Community College faculty who do not typically have the opportunity to be assisted by graduate students.

The internship culminated with a final design presentation. The presentation was attended by several company representatives including the company advisor. In the recording of the presentation, the company advisor stated: "With this project they were able to design the guarding that we needed, which is the real life problem, real life thing that we deal with every single day on our manufacturing floor. Basically by doing this, it allowed us to focus on other projects and allowed students an opportunity to see manufacturing in real life" ${ }^{8}$ 
A company representative that will be implementing the design stated: "The students basically took what we gave them, and ran with it. We basically gave them small details like what we will need, what are the requirements, and they fulfilled that $100 \% . "$

Interns incorporated their engineering design knowledge and understanding of manufacturing procedures gained in the classroom in to the design of the safety cages, thus better understanding how the class work related to the industry. This project benefitted the entire off-site team who gained a much greater understanding of the ejection molding manufacturing process and requirements.

\section{Conclusions}

As shown in Figure 2 below, this off-site internship model, with the engagement of the University graduate student provides both immediate and long-range benefits for all stakeholders. This model can be adapted to serve as a project in a classroom environment, allowing for authentic experiential learning throughout the program's curriculum.

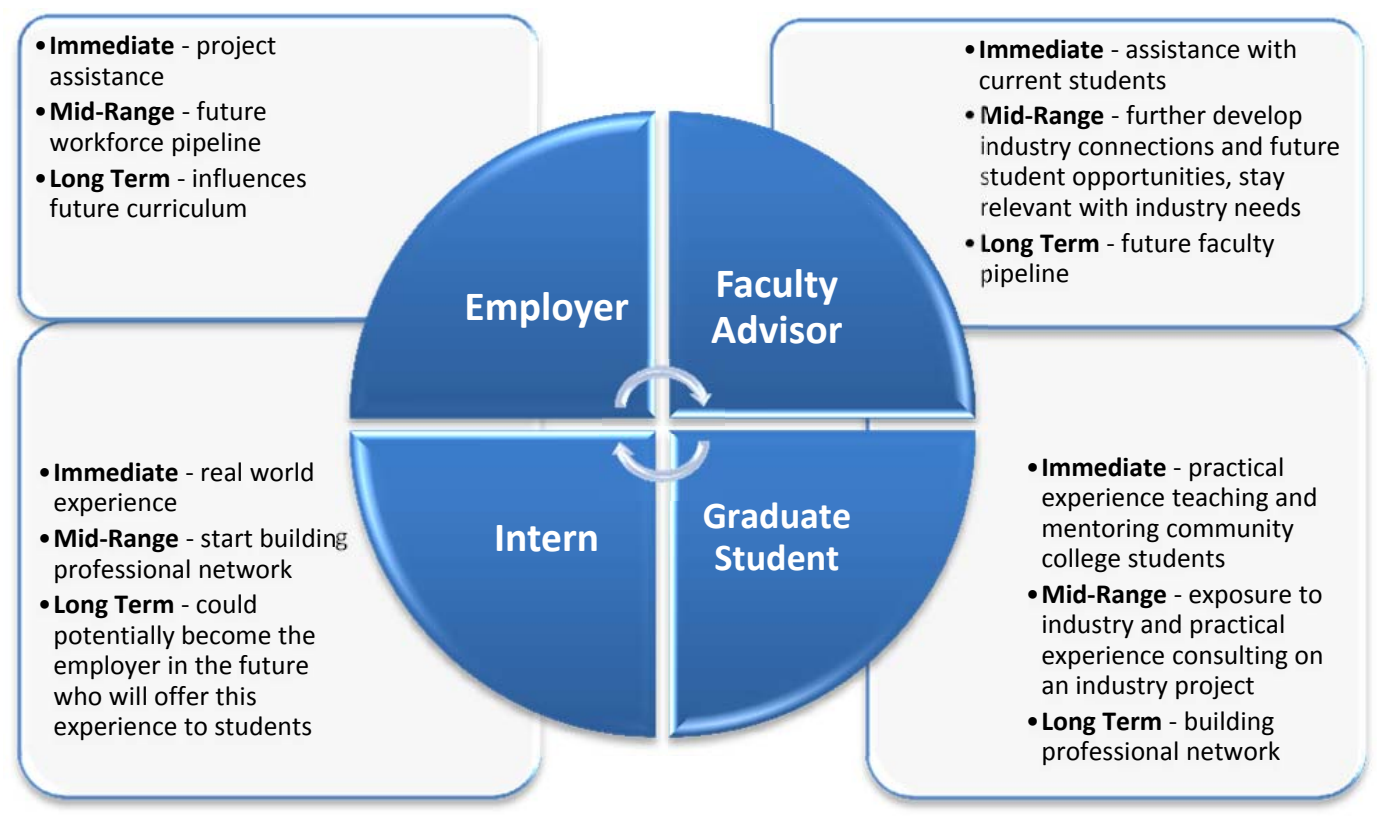

Figure 2 Stakeholder Benefits of the Off-site Internship model

By providing an industry relevant project to students, an employer gained a possible workable solution without using regular company resources and shorten time to solution implementation. While working with the students on this project, employer developed a relationship with the interns which enabled him to evaluate whether interns could fit future positions at the company. In the future, this could help further develop a workforce-ready student pipeline. While working with the faculty and students on the project, an employer was able to provide input into future curriculum, thus ensuring that future students are taught industry relevant skills.

The faculty advisor working on this project benefited from the assistance of the graduate student and was able to pass on their teaching experience, ensuring that there is a pipeline of future faculty familiar with the Community College student population and environment. While working with the employer, the faculty advisor was further exposed to the industry thus remaining current and can ensure that the 
curriculum is continuously updated to fit those needs. This experience also helped to further develop industry partnerships.

The university graduate student working on this project was exposed to a Community College environment in a holistic way; being mentored by the faculty advisor and mentoring and teaching a small group of Community College students. While working with the employer, the graduate student was introduced to the industry environment and helped increase their professional network.

The interns gained much needed industry experience, while still being able to maintain their permanent employment and family obligations. They were able to build a professional network with the possibility of future employment. A potential long-term benefit of this experience could be an increased number of off-site internships. After past interns see the benefit of the program, they may offer similar opportunities to future interns, thus continuing to influence future curriculum, mentorship and ultimately ensuring an industry-ready student pipeline.

\section{Acknowledgement}

This work is supported by the National Science Foundation under grant numbers DUE-1407160. Any opinions, findings, and conclusions or recommendations expressed in this material are those of the author(s) and do not necessarily reflect the views of the National Science Foundation.

\section{References}

\footnotetext{
${ }^{1}$ Kolb, D. A. (1984). Experiential learning: Experience as the source of learning and development (Vol. 1). Englewood Cliffs, NJ: Prentice-Hall.

${ }^{2}$ McCarthy, M. (2010). Experiential : Learning Theory: From Theory to Practice. Journal of Business \& Economics Research, 8(5), 131-140. Retrieved 13 , 2017, from http://www.cluteinstitute.com/ojs/index.php/JBER/article/viewFile/725/710

${ }^{3}$ Association of American Colleges and Universities. (2011). The LEAP Vison for Learning: Outcomes, Practices, Impact, and Employers' Views. Retrieved from https://www.aacu.org/sites/default/files/files/LEAP/leap_vision_summary.pdf

${ }^{4}$ Kuh, G.D. (AAC\&U, 2008). High-Impact Educational Practices: What They Are, Who Has Access to Them, and Why They Matter

${ }^{5}$ National Association of Colleges and Employers (NACE). (2011). Position Statement: U.S. Internships. Retrieved from http://www.naceweb.org/advocacy/position-statements/united-statesinternships.aspx?intlftnav

${ }^{6}$ Council for the Advancement of Standards in Higher Education (CAS), (2015). INTERNSHIP PROGRAMS CAS Contextual Statement. Retrieved from http://standards.cas.edu/getpdf.cfm?PDF=E86CFB4D-0B9E4853-6D82720BE0779895

${ }^{7}$ Advanced Manufacturing Partnership (AMP) Steering Committee. (2012). Report to the President: Capturing A Domestic Competitive Advantage in Advanced Manufacturing. Retrieved from
} 
https://www.whitehouse.gov/sites/default/files/microsites/ostp/amp_final_report_annex_3_education _and_workforce_development_july_update.pdf

${ }^{8}$ MassBay Community College: Advanced Manufacturing Transform Video. (2106). Retrieved from https://www.youtube.com/watch?v=Vg-RejHv52Q\&feature=youtu.be 